\title{
Effective Thermal Conductivity of Soda-Lime Silicate Glassmelts with Different Iron Contents Between $1100^{\circ} \mathrm{C}$ and $1500^{\circ} \mathrm{C}$
}

\author{
Laurent Pilon, ${ }^{\ddagger} \dagger$ Filip Janos, ${ }^{\S}$ and Rei Kitamura \\ ${ }^{\ddagger}$ Mechanical and Aerospace Engineering Department, University of California, Los Angeles 420 Westwood Plaza, Los Angeles, \\ California 90095-1597 \\ ${ }^{\S}$ Glass Service, Inc., Rokytnice 60, Vsetin CZ-755 01, Czech Republic \\ "Asahi Glass Corporation, Ltd, Production Technology Center, 1-1 Suehirocho, Tsurumi-ku, Yokohama-shi, \\ Kanagawa 230-0045, Japan
}

This study presents a simple method for retrieving the effective thermal conductivity of semitransparent glassmelts from measured temperature profiles. Effective thermal conductivity of molten glass at high temperature is an important thermophysical property that affects the glassmelting and forming processes and thus the quality of the final glass products. In semitransparent glassmelts, heat is transferred by both conduction and radiation. In the limiting case of optically thick glassmelts, typically featuring high iron content, thermal radiation can be treated as a diffusion process. The total heat flux can be expressed as the sum of a phononic and a radiative heat fluxes based on Fourier's law. For weakly absorbing glassmelts, the temperature profile may be strongly nonlinear particularly neat container walls due to the contribution from emission and absorption. Steady-state measurement techniques, such as the linear heat flux method, have been developed to measure glassmelt effective thermal conductivity at high temperatures. However, they typically use only three temperatures measurements and assume linear temperature profile in the glassmelt. The new retrieval method addresses these drawbacks particularly for weakly absorbing glassmelts featuring nonlinear temperature profiles. It is demonstrated with experimental data collected for sodalime silicate glasses with iron content ranging from 0.008 to $1.1 \mathrm{wt} \%$ and temperatures between $1100^{\circ} \mathrm{C}$ and $1550^{\circ} \mathrm{C}$.

\section{Introduction}

E FFECTIVE thermal conductivity of molten glass at high temperature is an important thermophysical property that affects the glassmelting and forming processes and therefore the quality of the final glass products. For example, the lifetime of glassmelting furnaces is strongly affected by the temperature of the refractory walls in contact with the glassmelt. In fact, refractory walls wear more rapidly for clear glassmelts compared with colored ones. ${ }^{1}$

Soda-lime silicate glass is the most common glass composition used in a wide range of glass products. For example, so-called solar control glass is a type of soda-lime silicate glass containing around $1 \mathrm{wt} \%$ of iron used in automotive windows. $^{2}$ Iron is added to absorb ultraviolet (UV) and infrared (IR) solar radiation to reduce the harmful effects of UV and the vehicle thermal load and to increase passenger comfort. Alternatively, extra-clear, low-iron content, sodalime silicate glasses are being developed for solar energy

J. Mauro-contributing editor technologies including photovoltaic ${ }^{3}$ and concentrated solar power. ${ }^{4,5}$ The low-iron content aims to minimize absorption and maximize system efficiency.

In semitransparent glassmelts at high temperature, heat is transferred by both conduction and radiation. In the limiting case of high-iron content glasses, radiation can be treated as a diffusion process. Then, the total heat flux can be expressed, based on Fourier's law, as the sum of a conductive and a radiative heat fluxes. ${ }^{6}$ However, for low-iron content glass, radiation may not be treated as a diffusion process. Then, the glassmelt temperature profile is strongly nonlinear as the effect of radiation becomes significant. ${ }^{1,7}$ Under these conditions, if the glassmelt is in contact with a wall, the temperature distribution depends also on the emissivity and reflectivity of the wall in a nontrivial way. 6,8

This study presents a simple methodology to retrieve the effective thermal conductivity from the temperature profile measured in glassmelt contained in a crucible heated from above. The methodology is applied to different soda-lime silicate glassmelts with compositions featuring low (extra-clear) to high (green and gray) iron content between $1100^{\circ} \mathrm{C}$ and $1550^{\circ} \mathrm{C}$.

\section{Background}

\section{(1) Rosseland Diffusion Approximation}

In semitransparent glassmelts at high temperature, heat is transferred by both conduction and radiation. In the limiting case of optically thick glassmelts, typically featuring highiron content, radiation can be treated as a diffusion process. ${ }^{6}$ Then, the total heat flux can be expressed as the sum of conductive and radiative heat fluxes both given by Fourier's law as

$$
\vec{q}_{\text {total }}=-k_{\mathrm{c}}(T) \nabla T-k_{\mathrm{rad}}(T) \nabla T=-k_{\mathrm{eff}}(T) \nabla T
$$

where $k_{\mathrm{c}}(T)$ and $k_{\mathrm{rad}}(T)$ are the conductive and radiative thermal conductivities, respectively. The effective thermal conductivity denoted by $k_{\mathrm{eff}}(T)$ is such that $k_{\mathrm{eff}}(T)=k_{c}(T)+k_{\mathrm{rad}}(T)$. Note that $k_{\mathrm{c}}(T), k_{\mathrm{rad}}(T)$, and $k_{\mathrm{eff}}(T)$ depend on temperature.

The Rosseland diffusion approximation is valid in the limiting case when the photon mean free path is much smaller than the characteristic length of the medium. Then, radiation can be treated as a diffusion process. It states that the radiative conductivity $k_{\mathrm{rad}}(T)$ can be expressed as ${ }^{9}$

$$
k_{\mathrm{rad}}(T)=\frac{16 n^{2} \sigma T^{3}}{3 \kappa_{R}}
$$

where $\sigma$ is the Stefan-Boltzmann constant $(\sigma=5.67 \times$ $10^{-8} \mathrm{~W} / \mathrm{m}^{2} \mathrm{~K}^{4}$ ) and $n$ is the index of refraction of the 
medium. The Rosseland mean absorption coefficient $\kappa_{R}$ can be computed from the spectral absorption coefficient $\kappa_{\lambda}$ and the refraction index $n_{\lambda}$ of the glassmelt according to ${ }^{9}$

$$
\frac{n^{2}}{\kappa_{R}}=\frac{\pi}{4 \sigma T^{3}} \int_{0}^{\infty} \frac{n_{\lambda}^{2}}{\kappa_{\lambda}} \frac{\mathrm{d} I_{b, \lambda}}{\mathrm{d} T} \mathrm{~d} \lambda
$$

where the blackbody spectral intensity under vacuum $I_{\mathrm{b}, \lambda}(T)$ is given by Planck's law and its derivative with respect to temperature is expressed as ${ }^{9}$

$$
\frac{\mathrm{d} I_{b, \lambda}}{\mathrm{d} T}=\frac{2 h c^{2}}{\lambda^{6} k_{\mathrm{B}} T^{2}} \frac{\exp \left(h c / \lambda k_{\mathrm{B}} T\right)}{\left[\exp \left(h c / \lambda k_{\mathrm{B}} T\right)-1\right]^{2}}
$$

where $h, \quad c$, and $k_{\mathrm{B}}$ are the Planck's constant $\left(h=6.626068 \times 10^{-34} \mathrm{~m}^{2} \mathrm{~kg} / \mathrm{s}\right)$, the speed of light in vacuum $(c=299792458 \mathrm{~m} / \mathrm{s})$, and the Boltzmann constant $\left(k_{\mathrm{B}}=1.3806503 \times 10^{-23} \mathrm{~m}^{2} \mathrm{~kg} / \mathrm{s}^{2} / \mathrm{K}\right)$, respectively.

Finally, the local temperature at any time and location in optically thick and quiescent glassmelts can be predicted by solving the energy conservation equation expressed as

$$
\rho(T) c_{\mathrm{p}}(T) \frac{\partial T}{\partial t}=\nabla \cdot\left(k_{\mathrm{eff}}(T) \nabla T\right)
$$

where $\rho(T)$ and $c_{\mathrm{p}}(T)$ are the density and specific heat of the glassmelt which also depend on temperature. In practice, the temperature profile varies almost linearly with space if the temperature difference across the domain is relatively small, as the local thermophysical properties do not change significantly far from the transition temperature. ${ }^{10}$

\section{(2) Combined Conduction and Radiation Heat Transfer}

In cases when radiation cannot be treated as a diffusion process, one needs to solve the energy conservation equation expressed in terms of the radiative heat flux $\vec{q}_{\text {rad }}$ as ${ }^{9,11}$

$$
\rho(T) c_{\mathrm{p}}(T) \frac{\partial T}{\partial t}=\nabla \cdot\left(k_{\mathrm{c}}(T) \nabla T\right)-\nabla \cdot \vec{q}_{\mathrm{rad}}
$$

Here, the divergence of the radiative heat flux is defined as (Modest, 2003)

$$
\nabla \cdot \vec{q}_{\mathrm{rad}}=\int_{0}^{\infty}\left(4 \pi n_{\lambda}^{2} I_{b, \lambda}-G_{\lambda}\right) d \lambda
$$

where $G_{\lambda}$ is the spectral fluence rate defined as $G_{\lambda}(\hat{r})=\int_{4 \pi} I_{\lambda}(\hat{s}, \hat{r}) d \Omega$. The intensity $I_{\lambda}(\hat{s}, \hat{r})$ at location $\hat{r}$ in direction $\hat{s}$ is governed by the radiative transfer equation (RTE). For an absorbing, emitting, but nonscattering media, the RTE can be written as ${ }^{9}$

$$
\hat{s} \cdot \nabla I_{\lambda}=-\kappa_{\lambda} I_{\lambda}+\kappa_{\lambda} n_{\lambda}^{2} I_{b, \lambda}
$$

where the spectral absorption coefficient is given by $\kappa_{\lambda}=4 \pi k_{\lambda} / \lambda$ with $k_{\lambda}$ being the imaginary part of the complex index of refraction $m_{\lambda}$ of the glassmelt defined as $m_{\lambda}=n_{\lambda}-i k_{\lambda}$. The temperature profile predicted by solving Eqs. (6)-(8) and the associated boundary conditions accounting for emission and reflection by the container wall may be strongly nonlinear particularly near the wall, as the effect of radiation becomes significant. ${ }^{7,11}$ This analysis leading to the temperature profile in the glassmelt was validated experimentally by Eryou and Glicksman ${ }^{8}$ with molten glass of known phononic thermal conductivity $k_{\mathrm{c}}(T)$ and spectral absorption coefficient at $1100^{\circ} \mathrm{C}-1300^{\circ} \mathrm{C}$ sandwiched between platinumlined ceramic plates with specified temperatures and predicted spectral reflectivity.

\section{(3) Effective Thermal Conductivity Measurements}

Experimental measurements of glass effective thermal conductivity at temperature above $600^{\circ} \mathrm{C}$ are complicated by the facts that (1) the glass may be molten, (2) radiative heat transfer may affect the measured temperature profile and/or heat flux, (3) experiments must be performed in high-temperature furnace with limited access, and (4) under thermally and sometimes chemically harsh environments. In addition, the measured glassmelt thermal conductivity is in fact the effective thermal conductivity $k_{\text {eff, which accounts for the }}$ combined effects of conduction and radiation.

Several measurement techniques have been developed to measure glassmelt effective thermal conductivity at high temperatures. They can be divided into transient and steadystate methods. ${ }^{10,12}$ Transient methods such as the hot wire method, ${ }^{13}$ various laser flash methods, ${ }^{13-15}$ the periodic heat flow method, ${ }^{16}$ and the needle probe method ${ }^{17,18}$ have been used to measure the thermal diffusivity of glassmelts. Then, one needs to measure density and specific heat to retrieve the glassmelt thermal conductivity. The laser flash method can be used for opaque glassmelt as it is based on the assumption that the laser radiation is absorbed near the glassmelt surface, that is, thermal radiation transfer can be treated as a diffusion process. This assumption is not valid for transparent glassmelts. ${ }^{19}$ Steady-state methods measure directly the effective thermal conductivity and include (i) the linear heat flow method, ${ }^{1}$ (ii) the interferometric method, ${ }^{7}$ and (iii) the radial heat flow method. ${ }^{10}$ This study focuses on steady-state methods for their simplicity and the fact that they directly measure the thermal conductivity. Finally, attempts have been made to partially correct the effect of radiation heat transfer on the temperature profile and retrieve the phononic (also referred as "true") thermal conductivity based on inverse methods requiring knowledge of the container's total hemispherical emissivity, the glassmelt spectral index of refraction and absorption coefficient in the infrared part of the spectrum as functions of temperature. $^{15,18,20}$

\section{(4) Linear Heat Flux Method}

The linear heat flow method" has been identified as "the most suitable" for measuring the effective thermal conductivity of glassmelts. ${ }^{10}$ It consists of inserting a thermocouple in a thick layer of glassmelt of thickness $L$ contained in a crucible heated from the top and measuring the temperature profile as a function of depth. The effective thermal conductivity of the glassmelt is determined from Fourier's law by assuming one-dimensional heat transfer, that is, the crucible sidewalls as perfectly insulated, so that $^{1}$

$$
k_{\mathrm{LHF}}(\bar{T})=\frac{q_{0}^{\prime \prime} L}{\left(T_{L}-T_{0}\right)}
$$

where $q_{0}^{\prime \prime}$ is the total steady-state heat flux through the glassmelt, while $T_{L}$ and $T_{0}$ are the temperatures at the free surface and bottom of the glassmelt, respectively. The effective thermal conductivity is estimated at the average glassmelt temperature $\bar{T}=\left(T_{0}+T_{L}\right) / 2$. The heat flux $q_{0}^{\prime \prime}$ is determined from the temperature difference across the crucible wall of thickness $d_{\mathrm{C}}$ based on one-dimensional Fourier's law so that ${ }^{1}$ 
Table I. Summary of the Composition and Depth of the Different Soda-Lime Silicate Glassmelts Investigated

\begin{tabular}{llcccc}
\hline Composition & \multicolumn{1}{c}{ Application } & $\mathrm{SiO}_{2}(\mathrm{wt} \%)$ & $\mathrm{Na}_{2} \mathrm{O}(\mathrm{wt} \%)$ & $\mathrm{CaO}(\mathrm{wt} \%)$ & $\mathrm{Fe}_{2} \mathrm{O}_{3}(\mathrm{wt} \%)$ \\
\hline 1 & Automotive (gray) & 69.8 & 13.3 & 8.3 & 1.10 \\
2 & Automotive (green) & 70.5 & 13.4 & 8.3 & 0.512 \\
3 & Building & 72.0 & 13.1 & 8.0 & 0.084 \\
4 & Solar cells & 71.4 & 13.85 & 7.5 & 0.008 \\
\hline
\end{tabular}

$$
q_{0}^{\prime \prime}=-k_{\mathrm{C}}\left(\bar{T}_{\mathrm{C}}\right) \frac{\left(T_{\mathrm{S}}-T_{0}\right)}{d_{\mathrm{C}}}
$$

where $T_{\mathrm{S}}$ is the measured outer surface crucible temperature. The crucible thermal conductivity is denoted by $k_{\mathrm{C}}\left(\bar{T}_{\mathrm{C}}\right)$ and is estimated at the average crucible temperature $\bar{T}_{\mathrm{C}}=\left(T_{\mathrm{S}}+T_{0}\right) / 2$. Then, the effective thermal conductivity is measured for different furnace temperatures and plotted as a function of $\bar{T}$. Finally, $k_{\text {eff }}(\bar{T})$ can be fitted as a function of $\bar{T}$ with a first- or second-order polynomial.

Note that this data analysis considers only three temperatures, namely, $T_{\mathrm{L}}, T_{0}$, and $T_{\mathrm{S}}$. This approach is based on the implicit assumption that the glassmelt temperature profile is linear. This is true in the limiting case when radiation can be treated as a diffusion process. In practice, this assumption is satisfied experimentally by considering "thick enough" glassmelts. ${ }^{1,10}$ Unfortunately, performing experiments in large crucible is prohibitively expensive and measurements may be affected by undesirable natural convection. Thus, this assumption may be difficult to achieve with extra-clear glasses. Moreover, the linear heat flux method assumes $k_{\text {eff }}(\bar{T})$ to be constant and estimated at the average temperature $\bar{T}$. However, the difference between $T_{0}$ and $T_{\mathrm{L}}$ may exceed $100^{\circ} \mathrm{C}$ to minimize experimental uncertainties. Over this temperature range, variations in effective thermal conductivity may need to be accounted for.

This study aims to develop a simple retrieval method addressing the drawbacks of the linear heat flux method particularly for low-iron content glassmelts, when the temperature profile may be nonlinear. Particular attention was paid to soda-lime silicate glasses with high and low-iron content between $1100^{\circ} \mathrm{C}$ and $1550^{\circ} \mathrm{C}$.

\section{Experiments and Data Analysis}

\section{(1) Samples}

Four soda-lime silicate glass samples with different iron oxide $\left(\mathrm{Fe}_{2} \mathrm{O}_{3}\right)$ contents were investigated. Note that they did not contain any elements for coloring. Table I summarizes the sample composition and their iron content. The $\mathrm{SiO}_{2}, \mathrm{Na}_{2} \mathrm{O}$,

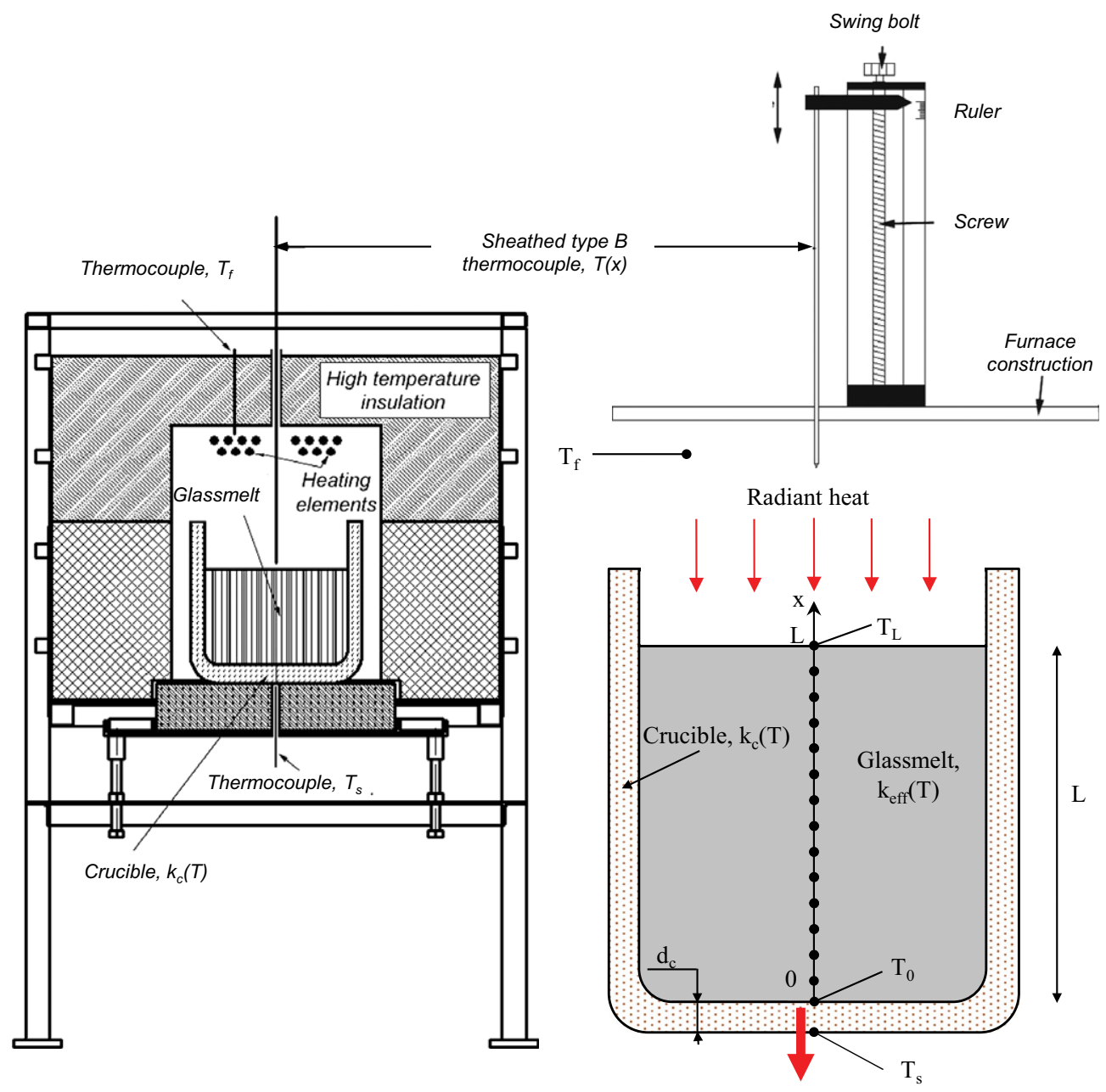

Fig. 1. Schematic of the experimental setup, coordinate system, and location of the different thermocouples. 


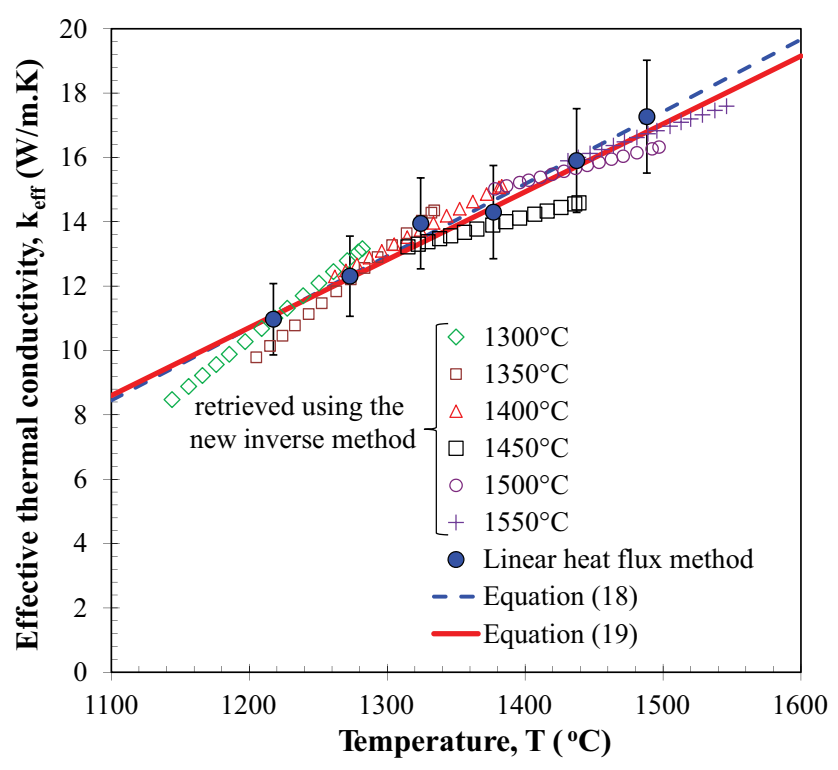

Fig. 2. Effective thermal conductivity of soda-lime silicate glassmelt of composition 1 retrieved using the conventional linear heat flux method [Eqs. (9) and (10)] and the new retrieval method for furnace temperature $T_{f}$ between $1300^{\circ} \mathrm{C}$ and $1550^{\circ} \mathrm{C}$ along with fitting lines given by Eqs. (18) and (19).

and $\mathrm{CaO}$ weight fractions were in the range $69-72 \mathrm{wt} \%$, $13-14 \mathrm{wt} \%$, and $7-9 \mathrm{wt} \%$, respectively. The iron content in glassmelt compositions $1,2,3$, and 4 was approximately 1.1 , $0.51,0.013$, and $0.008 \mathrm{wt} \%$, respectively. Soda-lime silicate glasses with compositions 1 and 2 corresponded to gray and green glasses used for automotive applications. Soda-lime silicate glasses with compositions 3 and 4 were clear and extra-clear soda-lime silicate glasses used for building and solar energy applications, respectively.

\section{(2) Experimental Setup}

Figure 1 schematically shows the experimental setup along with the coordinate system and dimensions. Cullets of the specified soda-lime silicate glass composition were crushed and melted in a high-alumina crucible to result in $35-40 \mathrm{~kg}$ of glassmelt. The custom-made crucible was $30 \mathrm{~cm} \times 30 \mathrm{~cm} \times 20 \mathrm{~cm}$ in volume and was $4 \mathrm{~mm}$ thick. It was made of $\sim 97 \%$ of $\mathrm{Al}_{2} \mathrm{O}_{3}, \sim 2 \%$ of $\mathrm{SiO}_{2}$, and $\sim 0.15 \mathrm{wt} \%$ of $\mathrm{Fe}_{2} \mathrm{O}_{3}$ with an estimated porosity of $17 \%{ }^{21}$ During the fabrication process, the crucible was sintered at $1600^{\circ} \mathrm{C}$. A new crucible was used for each glass composition. It was placed in a high-temperature furnace and heated from the top by $\mathrm{SiC}$ heating rods. The furnace temperature was set at temperature $T_{f}$ and increased from $1300^{\circ} \mathrm{C}$ up to $1550^{\circ} \mathrm{C}$ by $50^{\circ} \mathrm{C}$ increments. A dwell time of $24 \mathrm{~h}$ was allowed before any measurement. One-dimensional heat transfer prevailed for the following reasons (1) the crucible feature a very large cross section, (2) the thermal conductivity of the crucible was 4-32 times smaller than that of the glassmelt considered, (3) the heating elements were placed directly above the crucible and the furnace crown served as a reradiating surface, (4) the furnace was very well insulated and the crucible fitted tightly in with only a few millimeters of gap, and (5) the temperature profile was measured along the crucible center line to minimize edge effects. The steady-state depth of the glassmelt was denoted by $L$ and varied between 14 and $17 \mathrm{~cm}$ depending on the glass composition. It was larger for clearer glassmelts to minimize the effect of crucible emissivity and reflectivity on the retrieved thermal conductivity. Note that the peak emission wavelength $\lambda_{\max }$ given by Wien's displacement law $\lambda_{\max } T_{f}=2898 \mu \mathrm{m} \mathrm{K}$, at the furnace temperature $T_{\mathrm{f}}$ considered ranged between 1.6
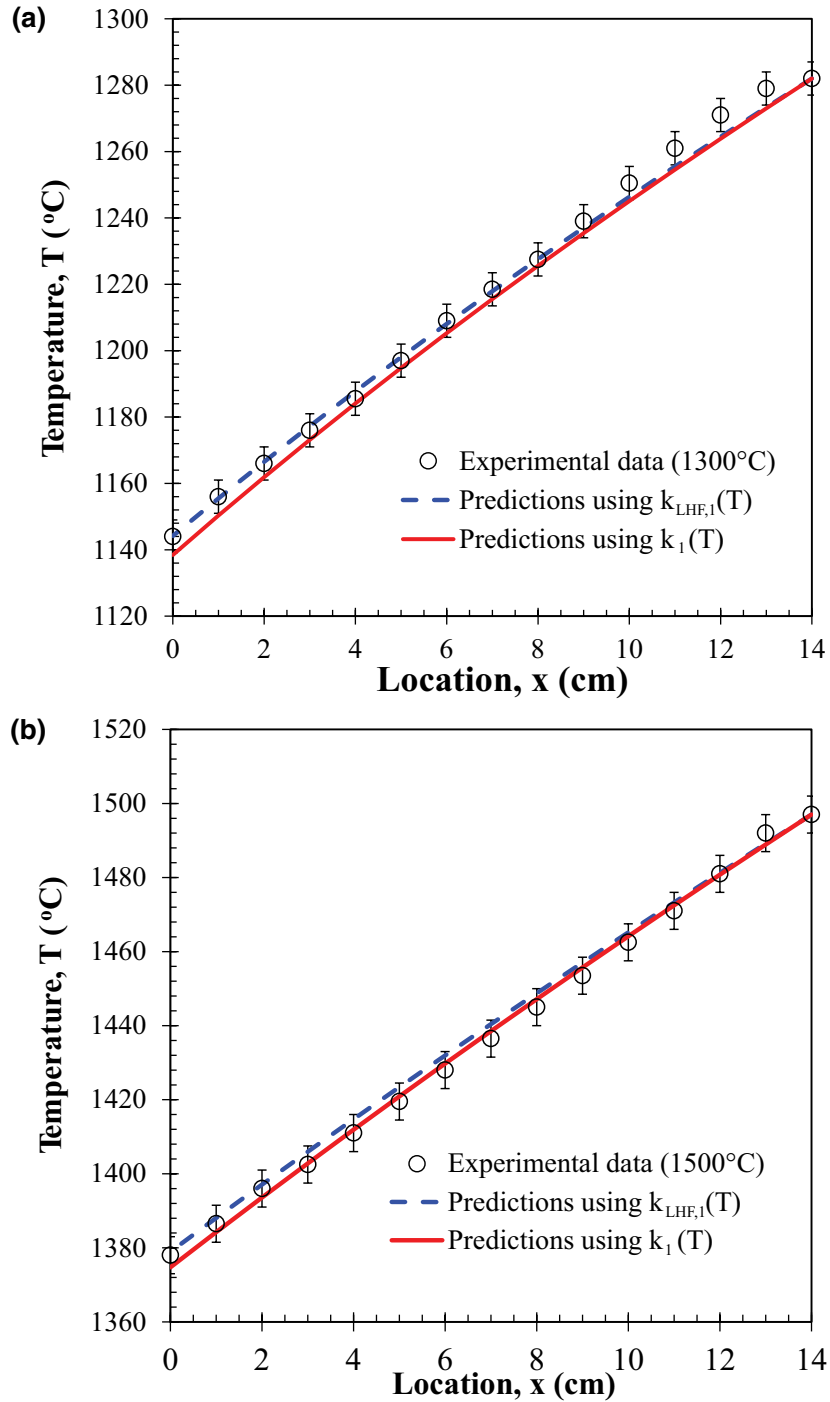

Fig. 3. Comparison between experimental temperature profiles and predictions using thermal conductivity $k_{\mathrm{LHF}, 1}(T)$ and $k_{1}(T)$, respectively, given by Eqs. (18) and (19) for glassmelt of composition 1 for furnace temperature $T_{f}$ of (a) $1300^{\circ} \mathrm{C}$ and (b) $1500^{\circ} \mathrm{C}$.

and $2.1 \mu \mathrm{m}$. For furnace temperatures of 1100 and $1500^{\circ} \mathrm{C}$, $90 \%$ of the radiation incident on the glassmelt is contained between 1 and $6.9 \mu \mathrm{m}$ and between 1 and $5.4 \mu \mathrm{m}$, respectively. The cut-off wavelength beyond which soda-lime silica glass can be considered opaque is about $2.8 \mu \mathrm{m}^{22,23}$ In addition, the absorption coefficient of various glasses (e.g., container, flint, and TV glass) in this wavelength range was reported to increase by a factor $2-3$ as temperature increases from $500^{\circ} \mathrm{C}$ to $1000^{\circ} \mathrm{C}$ for wavelength below $2.8 \mu \mathrm{m} .^{22-25}$ The mean free path of photons of wavelength $\lambda$ is defined as $h_{\lambda}=1 / \kappa_{\lambda}=\lambda / 4 \pi k_{\lambda}$, where $\kappa_{\lambda}$ and $\kappa_{\lambda}$ are the absorption coefficient and absorption index, respectively. The absorption index of soda-lime silica glasses reported in the literature at room temperature ranges from $4 \times 10^{-6}$ to $8 \times 10^{-3}$ for wavelength ranging between 1 and $6.9 \mu \mathrm{m} .^{26}$ Assuming that it increased by a factor $2-3$ as temperature increases from room temperature to $1000^{\circ} \mathrm{C}-1500^{\circ} \mathrm{C}$, the spectrally averaged photon mean free path averaged over the above-mentioned spectral windows corresponding to temperatures $1100^{\circ} \mathrm{C}$ and $1500^{\circ} \mathrm{C}$ can be estimated to be $\sim 0.1-0.2 \mathrm{~cm}$ for gray and green glasses, $0.3-0.5 \mathrm{~cm}$ for clear glasses, and $1-1.5 \mathrm{~cm}$ for low iron-content glass. These estimates suggest that all glassmelts considered were optically thick and the retrieved thermal conductivity was independent of sample thickness. 


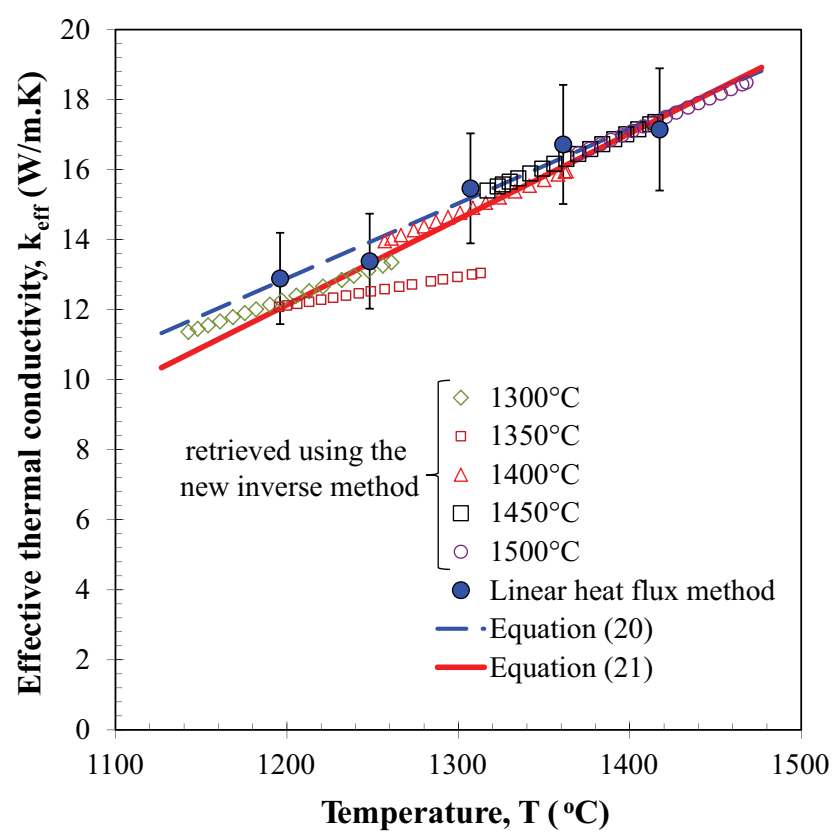

Fig. 4. Effective thermal conductivity of glassmelt of composition 2 retrieved using the conventional linear heat flux method [Eqs. (9) and (10)] and the new retrieval method for furnace temperature $T_{f}$ between $1300^{\circ} \mathrm{C}$ and $1500^{\circ} \mathrm{C}$ along with fitting lines given by Eqs. (20) and (21).

Temperature profile in the glassmelt was measured using a single straight type-B sheathed thermocouple with exposed junction (CeraTEMP ${ }^{\circledR} 80$ by JSP, Jičín, Czech Republic). The thermocouple was $65 \mathrm{~cm}$ long, while the PtRh30-PtRh6 wire and the $\mathrm{C} 799\left(99.7 \% \quad \mathrm{Al}_{2} \mathrm{O}_{3}\right)$ ceramic sheath were 1 and $7 \mathrm{~mm}$ in diameter, respectively. It was moved vertically with a precise mechanism mounted on the furnace construction and consisting of a swing bolt and a ruler. The temperature was recorded as the thermocouple was slowly inserted into the glassmelt under steady-state conditions. The temperature was recorded at $N$ discrete locations $x_{i}\left(0 \leq x_{i} \leq L\right)$ along the center line of the crucible. The crucible bottom wall was made of high alumina and had thickness $d_{\mathrm{C}}=4 \mathrm{~mm}$. Its effective thermal conductivity was provided by the manufacturer (SEPR Group, Saint Gobain SEFPRO, Le Pontet, France) and confirmed by our own measurements as

$$
k_{\mathrm{C}}\left(T_{\mathrm{C}}\right)=2 \times 10^{-6} T_{\mathrm{C}}^{2}-5.8 \times 10^{-3} T_{\mathrm{C}}+6.56
$$

where the crucible temperature $T_{\mathrm{C}}$ is given in ${ }^{\circ} \mathrm{C}$. The iron oxide impurities, the presence of pores and grains, the relatively large porosity, and the thickness suggest that the crucible was opaque for the wavelengths of interest in the visible and infrared part of the spectrum. ${ }^{27,28}$

Table I reports the glassmelt depth $L$ for each glassmelt composition, and the number of temperature measurements $N$ made from the top to bottom of the glassmelt. Finally, the temperature at the outer surface crucible $T_{\mathrm{S}}$ was also measured with a type-B thermocouple.

\section{(3) Experimental Uncertainties for the Linear Heat Flux Method}

The linear heat flow method relates the effective thermal conductivity of the glassmelt to the bottom and top temperatures $T_{0}$ and $T_{\mathrm{L}}$ and the heat flux $q_{0}^{\prime \prime}$ according to Eq. (9). The experimental uncertainty associated with the measurement of the heat flux $q_{0}^{\prime \prime}$, given by Eq. (10), can be estimated from error propagation analysis as ${ }^{29}$
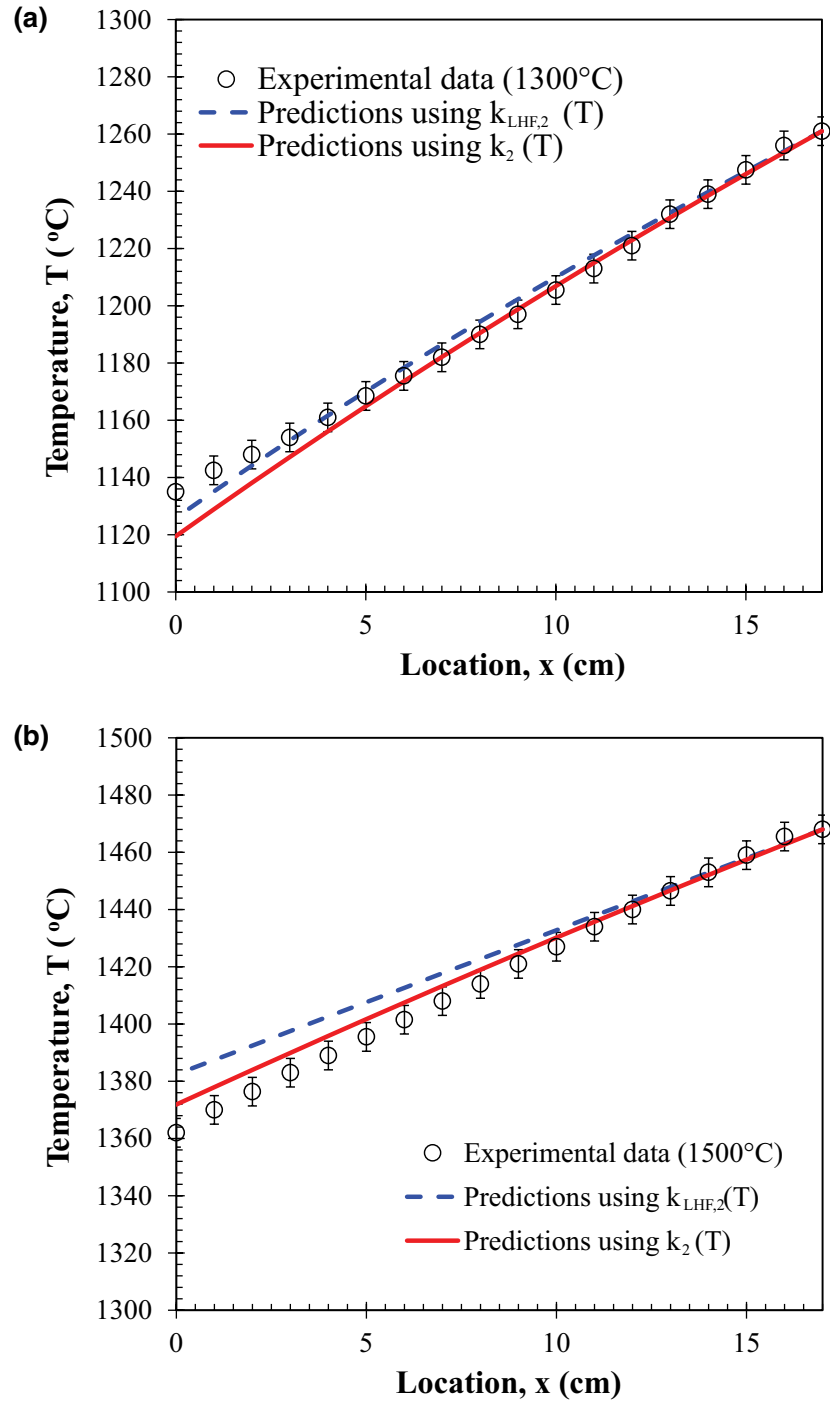

Fig. 5. Comparison between experimental temperature profiles and predictions using thermal conductivity $k_{\mathrm{LHF}, 2}(T)$ and $k_{2}(T)$, respectively, given by Eqs. (20) and (21) for glassmelt of composition 2 for furnace temperature $T_{f}$ of (a) $1300^{\circ} \mathrm{C}$ and (b) $1500^{\circ} \mathrm{C}$.

$$
\frac{\Delta q_{0}^{\prime \prime}}{q_{0}^{\prime \prime}}=\sqrt{\left(\frac{\Delta k_{\mathrm{C}}}{k_{\mathrm{C}}}\right)^{2}+\left(\frac{\Delta T_{\mathrm{S}}}{T_{\mathrm{S}}-T_{0}}\right)^{2}+\left(\frac{\Delta T_{\mathrm{L}}}{T_{\mathrm{S}}-T_{0}}\right)^{2}+\left(\frac{\Delta d_{\mathrm{C}}}{d_{\mathrm{C}}}\right)^{2}}
$$

Similarly, the experimental uncertainty associated with the measured glassmelt effective thermal conductivity $k_{\mathrm{LHF}}$ at temperature $\bar{T}$ is expressed as

$$
\frac{\Delta k_{\mathrm{LHF}}}{k_{\mathrm{LHF}}}=\sqrt{\left(\frac{\Delta q_{0}^{\prime \prime}}{q_{0}^{\prime \prime}}\right)^{2}+\left(\frac{\Delta L}{L}\right)^{2}+\left(\frac{\Delta T_{\mathrm{L}}}{T_{\mathrm{L}}-T_{0}}\right)^{2}+\left(\frac{\Delta T_{0}}{T_{\mathrm{L}}-T_{0}}\right)^{2}}
$$

The experimental uncertainty associated with $d_{\mathrm{C}}$ and $L$ was estimated to be $\Delta d_{\mathrm{C}} / d_{\mathrm{C}}=12.5 \%$ and $\Delta L / L=5 \%$. Similarly, the error associated with the crucible thermal conductivity was estimated as $\Delta k_{\mathrm{C}} / k_{\mathrm{C}}=5 \%$. The experimental uncertainties $\Delta T_{0}$ and $\Delta T_{\mathrm{L}}$ associated with the measured temperatures $T_{0}$ and $T_{\mathrm{L}}$ were caused by the fact that the glassmelt in the immediate vicinity of the thermocouple was radiatively nonhomogeneous and by heat conduction taking 


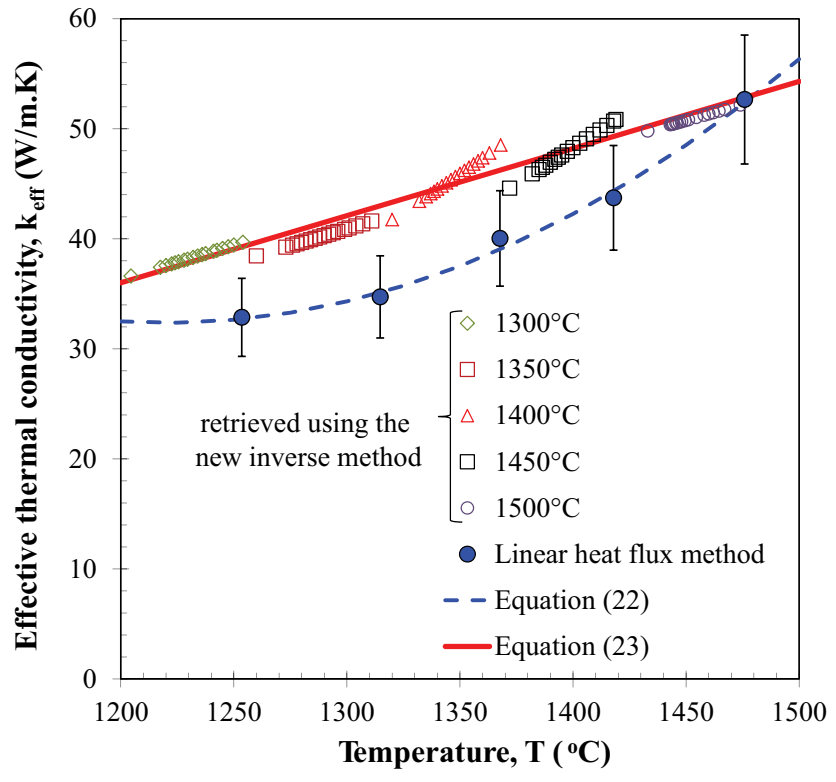

Fig. 6. Effective thermal conductivity of soda-lime silicate glassmelt of composition 3 retrieved using the conventional linear heat flux method [Eqs. (9) and (10)] and the new retrieval method for furnace temperature $T_{f}$ between $1300^{\circ} \mathrm{C}$ and $1500^{\circ} \mathrm{C}$ along with fitting lines given by Eqs. (22) and (23).

place along the thermocouple leads. Similar concerns exist in the measurement of $T_{\mathrm{S}}$. The temperature difference $T_{\mathrm{S}}-T_{0}$ ranged between 131 and $199 \mathrm{~K}$ for all glass compositions considered. These phenomena introduce errors that are difficult to estimate precisely, but were estimated to be $\Delta T_{S}=\Delta T_{0}=\Delta T_{\mathrm{L}}=5^{\circ} \mathrm{C}$.

\section{(4) New Retrieval Method}

To solve the coupled conduction and radiation problem governed by the energy conservation and radiation transfer equations, one needs to know the complex index of refraction of the glassmelts and the emissivity of the crucible as functions of wavelength and temperature. Unfortunately, these data are not currently available for the glass composition and crucible material used in this study. In addition, the absorption index is very sensitive to glass composition and using data reported in the literature would not be appropriate. Finally, from a practical point of view when simulating glassmelting furnaces and various forming processes, the Rosseland diffusion approximation is typically used. ${ }^{30}$ Thus, our goal was to develop a robust method to retrieve the effective thermal conductivity of glassmelts.

The energy conservation equation for one-dimensional steady-state combined conduction and radiation in optically thick glassmelts can be expressed as

$$
-k_{\mathrm{eff}}(T) \frac{\mathrm{d} T}{\mathrm{~d} x}=q_{0}^{\prime \prime}
$$

where $T(x)$ is the temperature at location $x$. The boundary conditions at the bottom $(x=0)$ and at the top $(x=L)$ are given by

$$
-k_{\mathrm{eff}}\left(T_{0}\right)\left(\frac{\mathrm{d} T}{\mathrm{~d} x}\right)(x=0)=q_{0}^{\prime \prime} \quad \text { and } \quad T(x=L)=T_{L}
$$

Assuming that the effective thermal conductivity is expressed as $k_{\mathrm{eff}}(T)=a+b T+c T^{2}$, one can integrate Eq. (14) between locations $x$ and $L$ using the boundary conditions given by Eq. (15) as (a)

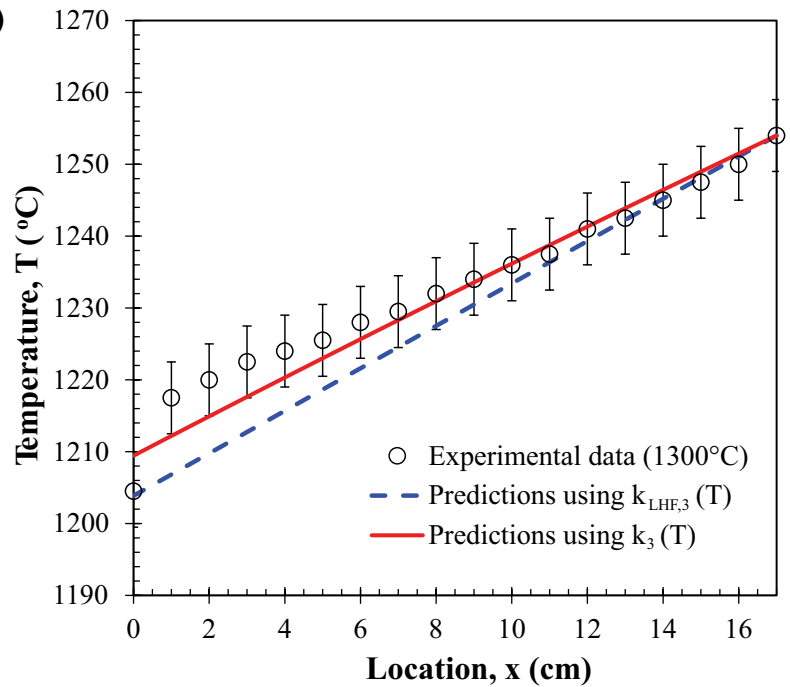

(b)

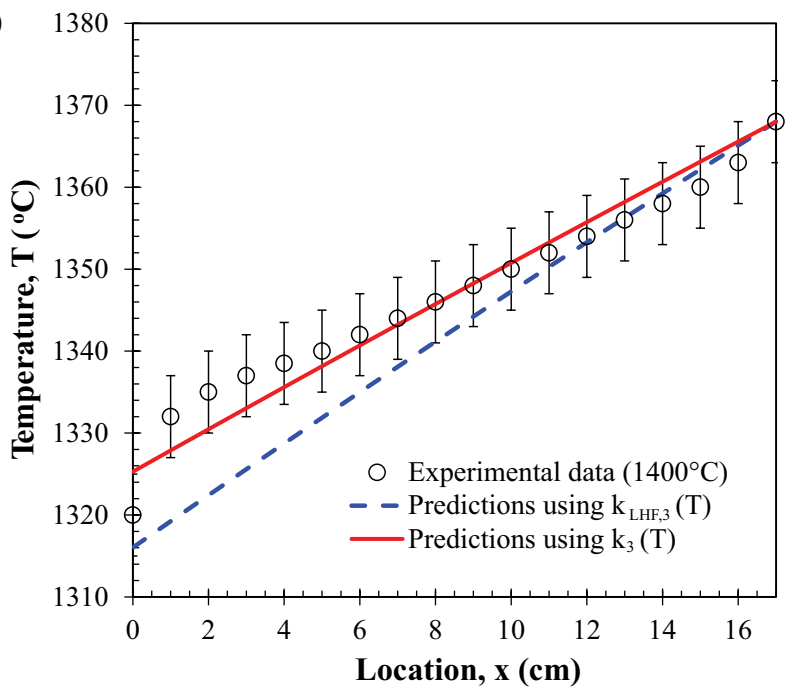

Fig. 7. Comparison between experimental temperature profiles and predictions using thermal conductivity $k_{\mathrm{LHF}_{3}(T)}$ and $k_{3}(T)$, respectively, given by Eqs. (20) and (21) for glassmelt of composition 3 for furnace temperature $T_{f}$ of (a) $1300^{\circ} \mathrm{C}$ and (b) $1400^{\circ} \mathrm{C}$.

$$
a\left(T-T_{\mathrm{L}}\right)+\frac{b}{2}\left(T^{2}-T_{\mathrm{L}}^{2}\right)+\frac{c}{3}\left(T^{3}-T_{\mathrm{L}}^{3}\right)=q_{0}^{\prime \prime}(L-x)
$$

where $T$ is the temperature at location $x$, that is, $T=T(x)$.

Then, the parameters $a, b$, and $c$ in the expression of the effective thermal conductivity can be retrieved from temperature measurements by minimizing the least square error defined as

$$
\begin{aligned}
\Delta & =\sum_{i=1}^{N} \delta_{i}^{2} \\
& =\sum_{i=1}^{N}\left[a\left(T_{i}-T_{\mathrm{L}}\right)+\frac{b}{2}\left(T_{i}^{2}-T_{\mathrm{L}}^{2}\right)+\frac{c}{3}\left(T_{i}^{3}-T_{\mathrm{L}}^{3}\right)-q_{0}^{\prime \prime}\left(\mathrm{L}-x_{i}\right)\right]^{2}
\end{aligned}
$$

where $N$ is the number of temperature measurements $T_{i}$ at discrete location $x_{i}$ in the glassmelt, that is, $T_{i}=T\left(x_{i}\right)$. In this study, the error $\Delta$ was minimized using the generalized reduced gradient nonlinear optimization method. ${ }^{31}$ Then, the effective thermal conductivity $k_{\mathrm{eff}}\left(T_{i}\right)$ was predicted for each 


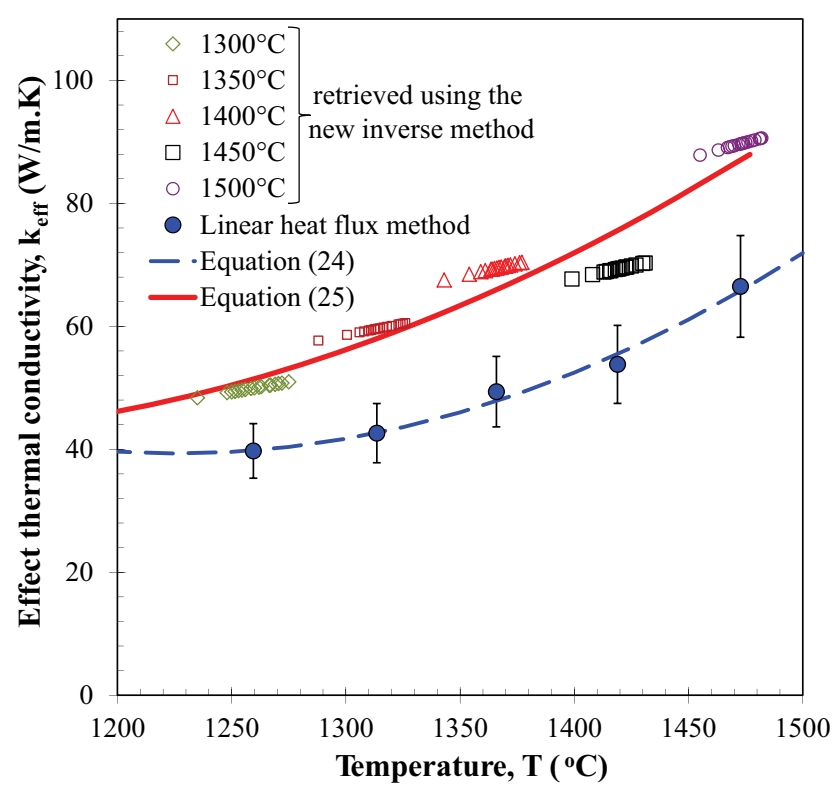

Fig. 8. Effective thermal conductivity of extra-clear soda-lime silicate glassmelt of composition 4 retrieved using the conventional linear heat flux method [Eqs. (9) and (10)] and the new retrieval method for furnace temperature between $1300^{\circ} \mathrm{C}$ and $1500^{\circ} \mathrm{C}$ along with fitting lines given by Eqs. (24) and (25).

location $x_{i}$. The retrieval of parameters $a, b$, and $c$ was repeated for each furnace temperature. All the data were then collectively fitted using the same order of the polynomial used in Eq. (16), but over a temperature range wider than individual datasets.

\section{Results and Discussions}

\section{(1) Effective Thermal Conductivity of Soda-Lime Silicate Glassmelt of Composition 1}

The effective thermal conductivity of soda-lime silicate glassmelt of composition 1 was retrieved using the linear heat flux method given by Eqs. (9) and (10) for furnace temperature. It was also retrieved using the new retrieval method assuming a linear relationship between $k_{\text {eff }}(T)$ and $T$, that is, $c=0$. Figure 2 shows the effective thermal conductivity of glassmelt of composition 1 retrieved using these two methods for six values of furnace temperature $T_{f}$, namely, $1300^{\circ} \mathrm{C}, 1350^{\circ} \mathrm{C}, 1400^{\circ} \mathrm{C}, 1450^{\circ} \mathrm{C}, 1500^{\circ} \mathrm{C}$, and $1550^{\circ} \mathrm{C}$. First, it is worth noting that the values of effective thermal conductivity obtained with the new retrieval method for the different furnace temperatures were consistent with one another. Second, the effective thermal conductivity data retrieved by the linear heat flux method and by the new retrieval method were in good agreement for the temperature range considered. In fact, the values retrieved with the new retrieval method fell within the experimental uncertainty of the values estimated using the linear heat flux method. It increased from 8 to $17 \mathrm{~W} \cdot(\mathrm{m} \cdot \mathrm{K})^{-1}$ as the glassmelt temperature increases from $1150^{\circ} \mathrm{C}$ to $1550^{\circ} \mathrm{C}$.

The effective thermal conductivity data [in $\left.\mathrm{W} \cdot(\mathrm{m} \cdot \mathrm{K})^{-1}\right]$ retrieved by the linear heat flow method were linearly fitted as

$$
k_{\mathrm{LHF}, 1}(T)=0.022 T-16.2
$$

where the temperature $T$ is expressed in ${ }^{\circ} \mathrm{C}$ and ranges between $1150^{\circ} \mathrm{C}$ and $1550^{\circ} \mathrm{C}$. The linear fit of the effective thermal conductivity retrieved by the new retrieval method was very similar and given by

$$
k_{1}(T)=0.021 T-14.6
$$

For both fits, the coefficient of determination exceeded 0.95 .

Figure 3 compares the experimentally measured temperature profile with those predicted by solving the one-dimensional steady-state energy conservation equation using the expressions of effective thermal conductivity given by Eqs. (18) and (19) for furnace temperature $T_{f}$ of (a) $1300^{\circ} \mathrm{C}$ and (b) $1500^{\circ} \mathrm{C}$. It shows that the temperature profiles predicted using the effective thermal conductivity given by either Eqs. (18) or (19) were almost linear and identical and were in good agreement with experimental measurements. These linear temperature profiles suggest that they were unaffected by the crucible emission and absorption and that the glassmelt was optically thick. In other words, thermal radiation could be treated as a diffusion process as the photon mean free path was a few hundreds of nanometers, as discussed previously.

\section{(2) Effective Thermal Conductivity of Soda-Lime Silicate Glassmelt of Composition 2}

Figure 4 shows the effective thermal conductivity of sodalime silicate glassmelt of composition 2 retrieved using the two above-described methods for furnace temperature $T_{f}$ set at $1300^{\circ} \mathrm{C}, 1350^{\circ} \mathrm{C}, 1400^{\circ} \mathrm{C}, 1450^{\circ} \mathrm{C}$, and $1500^{\circ} \mathrm{C}$. Here also, the new method retrieved values of effective thermal conductivity that were consistent with one another and similar to those measured by the linear heat flux method. Deviations of the retrieved effective thermal conductivity at $T_{f}=1350^{\circ} \mathrm{C}$ with respect to the others can be interpreted as error propagation from the experimental measurements to the retrieved thermal conductivity. However, they fell within the range of experimental uncertainty associated with the linear heat flux method. Overall, the effective thermal conductivity was found to increase from 11 to $18.5 \mathrm{~W} \cdot(\mathrm{m} \cdot \mathrm{K})^{-1}$ as temperature increased from $1150^{\circ} \mathrm{C}$ to $1450^{\circ} \mathrm{C}$.

Moreover, the effective thermal conductivity $\left[\right.$ in $\mathrm{W} \cdot(\mathrm{m} \cdot \mathrm{K})^{-1}$ ] estimated using the linear heat flow method was fitted as

$$
k_{\mathrm{LHF}, 2}(T)=0.021 T-12.8
$$

Alternatively, the effective thermal conductivity retrieved using the new retrieval method was linearly fitted as

$$
k_{2}(T)=0.025 T-17.3
$$

In both equations, the glassmelt temperature $T$ is expressed in ${ }^{\circ} \mathrm{C}$ and ranged between $1150^{\circ} \mathrm{C}$ and $1500^{\circ} \mathrm{C}$ and the coefficient of determination $R^{2}$ exceeded 0.95 .

The effective thermal conductivity of soda-lime silicate glass of composition 2 was slightly larger than that of composition 1. This can be attributed to the smaller iron content in composition 2 compared with glassmelts of composition 1, as indicated in Table I. However, a reduction in $\mathrm{Fe}_{2} \mathrm{O}_{3}$ content from 1.1 to $0.51 \mathrm{wt} \%$ resulted in a small increase of $\sim 10 \%$ in the effective thermal conductivity. This suggests that beyond a certain iron content, the medium is optically thick and that the iron content has little effect upon the thermal conductivity.

Figure 5 compares the experimental temperature profile in the glassmelt of composition of composition 2 for furnace temperature $T_{f}$ of (a) $1300^{\circ} \mathrm{C}$ and (b) $1500^{\circ} \mathrm{C}$ with those predicted by solving the one-dimensional steady-state energy conservation equation using the expressions of effective thermal conductivity given by either Eqs. (20) or (21). Here also, the temperature predictions agreed well with experimental measurements. However, the temperature profile predicted using $k_{\mathrm{LHF}, 2}(T)$ showed larger deviation from experimental data at $T_{f}=1500^{\circ} \mathrm{C}$. 

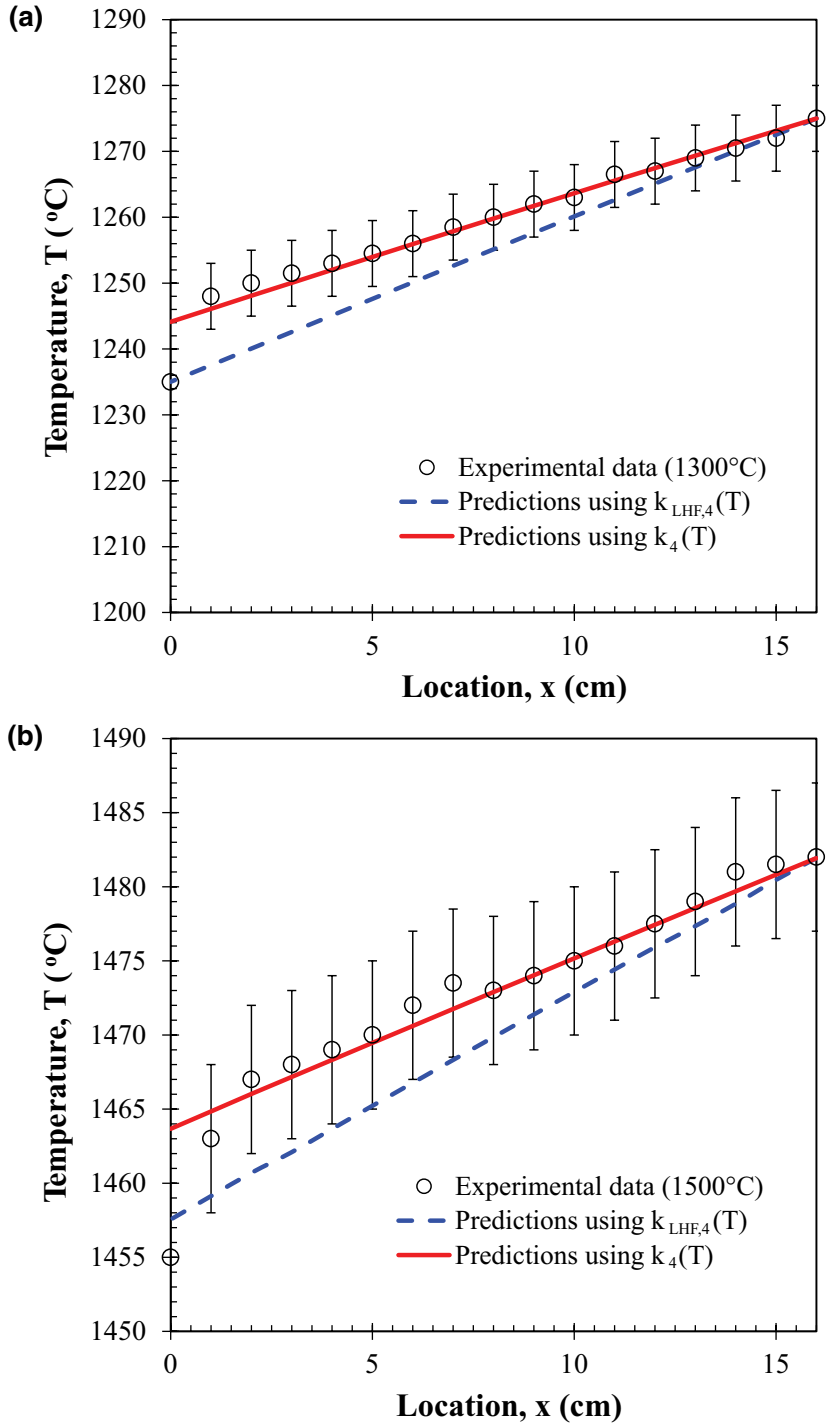

Fig. 9. Comparison between experimental temperature profiles and predictions using thermal conductivity $k_{\mathrm{LHF}, 4}(T)$ and $k_{4}(T)$, respectively, given by Eqs. (24) and (25) for glassmelt of composition 4 for furnace temperature $T_{f}$ of (a) $1300^{\circ} \mathrm{C}$ and (b) $1500^{\circ} \mathrm{C}$.

\section{(3) Effective Thermal Conductivity of Soda-Lime Silicate Glassmelt of Composition 3}

Figure 6 compares the effective thermal conductivity of soda-lime silica glassmelt of composition 3 retrieved using the linear heat flow method and the new retrieval method for furnace temperature of $1300^{\circ} \mathrm{C}, 1350^{\circ} \mathrm{C}, 1400^{\circ} \mathrm{C}, 1450^{\circ} \mathrm{C}$, and $1500^{\circ} \mathrm{C}$. It shows significant differences between the effective thermal conductivities retrieved by the linear heat flux method and by the new retrieval method. However, regardless of the method, it is evident that the effective thermal conductivity of glassmelt with composition 3 was significantly larger than that of glassmelts with compositions 1 and 2. This can be attributed to the fact that these compositions features larger iron contents making them more opaque resulting in smaller radiative thermal conductivity $k_{\mathrm{rad}}(T)$ compared with that of composition 3 .

Moreover, the effective thermal conductivity [in $\mathrm{W} \cdot(\mathrm{m} \cdot \mathrm{K})^{-1}$ ] retrieved using the linear heat flux method was fitted with a second-order polynomial as

$$
k_{\mathrm{LHF}, 3}(T)=3.1 \times 10^{-4} T^{2}-0.747 T+487.8
$$

Similarly, the effective thermal conductivity retrieved by the new retrieval method was fitted as

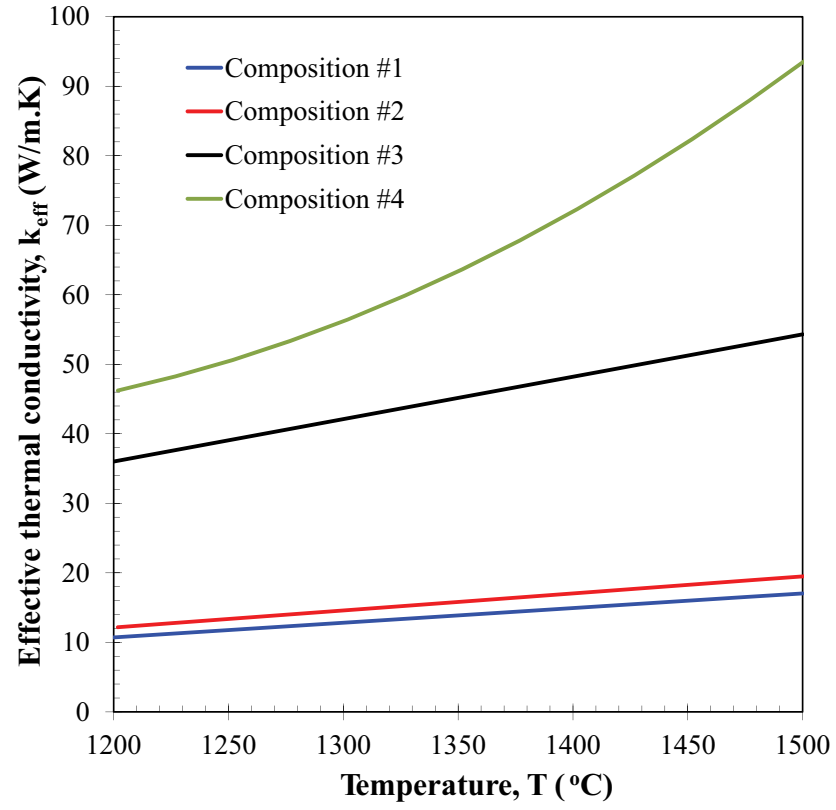

Fig. 10. Summary of the effective thermal conductivity of various soda-lime silicate glassmelts with high (compositions 1 and 2) and low (compositions 3 and 4) retrieved using the new retrieval method.

$$
k_{3}(T)=0.061 T-37.2
$$

where the temperature $T$ is expressed in ${ }^{\circ} \mathrm{C}$ and ranged between $1200^{\circ} \mathrm{C}$ and $1500^{\circ} \mathrm{C}$. The coefficient of determination was 0.96 and did not improve by considering a second-order polynomial.

To identify the best method of determining the glassmelt effective thermal conductivity, Fig. 7 compares the temperature profile measured experimentally at furnace temperatures $T_{f}$ of (a) $1300^{\circ} \mathrm{C}$ and (b) $1400^{\circ} \mathrm{C}$ with those predicted by using the effective thermal conductivity given by Eqs. (22) and (23). It is evident that the temperature profiles predicted by using $k_{3}(T)$ agreed well with experimental data for both values of $T_{f}$. However, the temperature profile for furnace temperature at $1400^{\circ} \mathrm{C}$ obtained with $k_{\mathrm{LHF}, 3}(T)$ differs significantly from experimental data.

Overall, the new retrieval method seems to perform better in retrieving the glassmelt effective thermal conductivity. This is due to the fact that it makes use of all the temperature measurements and provides a self-consistent approach accounting for temperature-dependent thermal conductivity. This makes it less sensitive to nonlinear temperature profile near the crucible walls which can be significant for clearer glassmelts. In other words, the linear heat flux method measures the apparent thermal conductivity, whereas the new method proposed aims to measure the effective thermal conductivity. For optically thick glassmelts, apparent and effective thermal conductivities are almost identical.

Finally, comparing the temperature profiles shown in Figs. 3, 5, and 7 for opaque glassmelts with compositions 1 and 2 and clearer glassmelt with composition 3 clearly illustrates the effect of the container wall on the temperature profile near the bottom of the crucible $(x=0 \mathrm{~m})$ as the glassmelt iron content decreases and the furnace temperature increases. Indeed, the effect of the wall emissivity on the temperature profile is apparent within 2-4 cm from the wall. This corroborates with estimates of the photon mean free path in clear glass as previously discussed. 


\section{(4) Effective Thermal Conductivity of Soda-Lime Silicate Glassmelt of Composition 4}

The extra-clear, low-iron content, soda-lime silicate glassmelt with composition 4 had iron content less than $0.01 \mathrm{wt} \%$. Figure 8 shows the effective thermal conductivity as a function of temperature estimated using the linear heat flux method and the new retrieval method. It is evident that large discrepancies existed between the two datasets. The linear heat flow method underestimated the effective thermal conductivity estimated by the new retrieval method by up to $27 \%$.

Moreover, fitting of the effective thermal conductivity retrieved with the linear heat flux method with a secondorder polynomial yielded

$$
k_{\mathrm{TLF}, 4}(T)=4.3 \times 10^{-4} T^{2}-1.062 T+690.2
$$

Similarly, the effective thermal conductivity data estimated using the new retrieval method were fitted to

$$
k_{4}(T)=2.8 \times 10^{-4} T^{2}-0.608 T+367.5
$$

where temperature $T$ is expressed in ${ }^{\circ} \mathrm{C}$ and varies between $1200^{\circ} \mathrm{C}$ and $1500^{\circ} \mathrm{C}$.

Figure 9 compares the experimental temperature profile in the glassmelt of composition 4 for furnace temperature $T_{f}$ of (a) $1300^{\circ} \mathrm{C}$ and (b) $1500^{\circ} \mathrm{C}$ with those predicted using the effective thermal conductivity $k_{\mathrm{LHF}, 4}(T)$ and $k_{4}(T)$ given by Eqs. (24) and (25). It shows very large discrepancies between experimental data and predictions using $k_{\mathrm{LHF}, 4}(T)$ throughout the glassmelt except for the bottom and surface glassmelt temperatures $T_{0}$ and $T_{\mathrm{L}}$. In contrast, temperature profiles predicted using $k_{4}(T)$ show good agreement with experimental data except in the immediate proximity of the crucible bottom. These results confirm that the new retrieval method is more appropriate in estimating the effective thermal conductivity of glassmelts particularly if the iron content is relatively low $(<0.1 \mathrm{wt} \%)$.

\section{Conclusion}

This study presented a simple method for retrieving the effective thermal conductivity of molten glass from temperature profile measurements. It offers an alternative to the commonly used linear heat flow method based on three temperature measurements at the surface of the glassmelt and across the crucible bottom wall. The two methods retrieved similar values of effective thermal conductivity for opaque glasses with relatively high-iron content. However, for glassmelts with iron content less than $0.1 \mathrm{wt} \%$, the linear heat flow method systematically underestimated the effective thermal conductivity and did not capture the nonlinear temperature profile. Instead, the new retrieval method used all temperature measurements within the glassmelt and predicted the measured temperature profile relatively accurately for all glass compositions and all furnace temperatures considered.

Figure 10 summarizes the retrieved effective thermal conductivity for the four different glassmelts between $1100^{\circ} \mathrm{C}$ and $1500^{\circ} \mathrm{C}$. High-iron content glassmelts (compositions 1 and 2) have a significantly smaller effective thermal conductivity than low-iron content glassmelts (compositions 3 and 4). These measurements will be useful in designing and operating glassmelting furnaces and forming processes.

\section{Acknowledgment}

The authors thank Prof. Raymond Viskanta from Purdue University for useful discussion and for his review of an earlier version of this manuscript.

\section{References}

${ }^{1}$ L. Kruszewski, "Total Heat-Transmission Coefficients of Amber and Green Glasses in Temperatures of Melting Range," J. Am. Ceram. Soc., 44 [7] 333-9 (1961).

${ }^{2}$ T. Uchino, K. Nakaguchi, Y. Nagashima, and T. Kondo, "Prediction of Optical Properties of Commercial Soda-Lime-Silicate Glasses Containing Iron," J. Non-Cryst. Solids, 261 [1-3] 72-8 (2000).

${ }^{3}$ S. V. Thomsen, R. Hulme, L. M. Landa, and K. A. Landa, "Low Iron High Transmission Float Glass for Solar Cell Applications and Method for Making Same"; US Patent No. 7,557,053 B2, 2009.

${ }^{4}$ L. Ventelon, O. Bouesnard, and B. Cosijns, "Mirror"; U.S. Patent Application, US 2011/0267713 A1, 2011.

${ }^{5}$ L. Ventelon and O. Bouesnard, "Solar Energy Reflector"; U.S. Patent Application, US 2011/0220098 A1, 2011.

${ }^{6}$ R. Viskanta and T. H. Song, "On the Diffusion Approximation for the Radiation Transfer in Glass," Glastechnische Berichte, 58 [4] 80-6 (1985).

${ }^{7}$ E. E. Anderson and R. Viskanta, "Effective Thermal Conductivity for Heat Transfer Through Semitransparent Solids," J. Am. Ceram. Soc., 56 [10] 541-6 (1973).

${ }^{8}$ N. D. Eryou and L. R. Glicksman, "An Experimental and Analytical Study of Radiative and Conductive Heat Transfer in Molten Glass," ASME J. Heat Transfer, 94 [2] 224-30 (1972).

${ }^{9}$ M. F. Modest, Radiative Heat Transfer. Taylor and Francis, New York, NY, 2003.

${ }^{10} \mathrm{~A}$. Blazek and J. Endrys, "Review of Thermal Conductivity Data in Glass. Part II. Thermal Conductivity at High Temperatures"; pp. 33-100 in International Commission on Glass, Charleroi, Belgium, 1983.

${ }^{11}$ R. Viskanta and R. J. Grosh, "Effect of Surface Emissivity on Heat Transfer by Simultaneous Conduction and Radiation," Int. J. Heat Mass Transfer, 5 [8] 729-34 (1962).

${ }^{2}$ J. Endrys, A. Blazek, and J. Ederova, "Experimental Determination of the Effective Thermal Conductivity of Glass by Steady-State Method," Glass Sci. Technol., 66 [6-7] 151-7 (1993).

${ }^{13}$ H. Hasegawa, H. Ohta, H. Shibata, and Y. Waseda, "Recent Development in the Investigation on Thermal Conductivity of Silicate Melts," High Temp. Mater. Processes (London), 31 [4-5] 491-9 (2012).

${ }^{14}$ A. Shibata, H. Suzuki, and H. Ohta, "Measurement of Thermal Transport Properties for Molten Silicate Glasses at High Temperatures by Means of a Novel Laser Flash Technique," Mater. Trans., 46 [8] 1877-81 (2005).

${ }^{15}$ H. Ohta, H. Shibata, and T. Kasamoto, "Estimation of Heat Transfer of a Front-Heating Front-Detection Laser Flash Method Measuring Thermal Conductivity for Silicate Melts at High Temperatures," ISIJ Int., 46 [3] 43440 (2006)

${ }^{16} \mathrm{~A}$. F. Van Zee and C. I. Babcock, "A Method for the Measurement of Thermal Diffusivity of Molten Glass," J. Am. Ceram. Soc., 34 [8] 244-50 (1951).

${ }^{17}$ H. Kiyohashi, N. Hayakawa, S. Aratani, and H. Masuda, "Thermal Conductivity Measurements of Float Glass at High Temperatures by Needle Probe Method," J. Ceram. Soc. Jpn., 108 [4] 381-6 (2000).

${ }^{18}$ K. Kiyohashi, N. Hatakawa, S. Aratani, and H. Masuda, "Thermal Conductivity of Heat Absorbed Soda-Lime-Silicate Glasses at High Temperatures," High Temp. High Pressures, 34 [2] 127-252 (2002).

${ }^{19}$ H. Wang, W. D. Porter, R. B. Dinwiddie, and C. Jian, "G-Plus Report to Owens Corning -Thermophysical Properties of Glasses"; Technical Report ORNL/TM-2004/72, Oak Ridge National Laboratory, 2004.

${ }^{20} \mathrm{~T}$. Kunc, M. Lallemand, and J. B. Saulnier, "Some New Developments on Coupled Radiative-Conductive Heat Transfer in Glasses-Experiments and Modelling," Int. J. Heat Mass Transfer, 27 [12] 2307-19 (1984).

${ }^{21}$ P-D Refractories CZ, Technical Data for Corundum Bricks-Cast and Fired, Brand A98KF. Available at: http://www.mslz.cz/docs/568.pdf, 2013.

${ }^{22}$ R. Viskanta and J. Lim, "Transient Cooling of a Cylindrical Glass Gob," J. Quant. Spectrosc. Radiat. Transfer, 73 [2-5] 481-90 (2002).

${ }^{23}$ A. M. Lankhorst and A. J. Faber, "Spectral Radiation Model for Simulation of Heat Transfer in Glass Melts," Glass Technol.: Eur. J. Glass Sci. Technol. A, 49 [2] 73-82 (2008).

${ }^{24}$ C. Ades, T. Toganidis, and J. P. Traverse, "High Temperature Optical Spectra of Soda-Lime-Silica Glasses and Modelization in View of Energetic Applications," J. Non-Cryst. Solids, 125 [3] 272-9 (1990).

${ }^{25}$ J. P. Traverse, C. Ades, and T. Toganidis, "Optical Properties of HighTemperature of Molten Soda-Lime-Silica Glasses Containing Iron-Oxide," Revue Internationale des Hautes Températures et des Réfractaires, 28 [2] 49-58 (1992).

${ }^{26}$ M. Rubin, "Optical Constants and Bulk Optical Properties of Soda Lime Silica Glasses for Windows," Solar Energy Mater., 12, 275-88 (1985).

${ }^{27}$ J. G. J. Peelen and R. Metselaar, "Light Scattering by Pores in Polycrystalline Materials: Transmission Properties of Alumina," J. Appl. Phys., 45 [1] 216 (1974).

${ }^{28}$ R. Apetz and M. P. B. van Bruggen, "Transparent Alumina: A LightScattering Model," J. Am. Ceram. Soc., 86 [3] 480-6 (2003).

${ }^{29}$ A. F. Mills and B. H. Chang, Error Analysis of Experiments: A Manual for Engineering Students. University of California, Los Angeles, CA, 49 pp, 2004.

${ }^{30}$ M. K. Choudhary, R. Venuturumilli, and M. R. Hyre, "Mathematical Modeling of Flow and Heat Transfer Phenomena in Glass Melting, Delivery, and Forming Processes," Int. J. Appl. Glass Sci., 1 [2] 188-214 (2010).

${ }^{31}$ L. S. Lasdon, A. D. Waren, A. Jain, and M. Ratner, "Design and Testing of a Generalized Reduced Gradient Code for Nonlinear Programming," $A C M$ Trans. Math. Softw., 4 [1] 34-50 (1978). 